\title{
Integration of Renewable Sources in Buildings - Case Study
}

\author{
B. Reis ${ }^{1}$ and P. Jota ${ }^{2}$ \\ ${ }^{1}$ Rua Francisca Leão Corre 165, 31.170-450 - Belo Horizonte (Brazil) \\ Phone/Fax number: +55 03198748 2081, e-mail: brenda_reis.1994@outlook.com \\ ${ }^{2}$ Department of Electrical Engineering \\ CEFET-MG \\ Belo Horizonte, Minas Gerais (Brazil) \\ E-mail: prsj@cefetmg.br
}

\begin{abstract}
Distributed generation has shown a great expansion in the last years with the improvement of new sources of energy. These renewable sources are increasingly efficient and accessible, providing more sustainable systems with less losses and lower environmental impacts. This work deals with possible configurations for a local electric power generation systems and the use of energy devices. A project for the improvement of a distributed generation system integrated to a building with an addition of a complementary source and of energy storage elements is made, aiming at reducing the energy consumption acquired from the local concessionary, islanding the building during peak hours, when the Rate is more expensive. Some of the characteristics and measurements carried out in the building of the Centro de Pesquisa em Energia Inteligente (CPEI) located at Campus II of the Centro Federal de Educação Tecnológica de Minas Gerais (CEFET-MG) are adopted as a basis.
\end{abstract}

\section{Key words}

Distributed generation, renewable energy, energy devices, complementary source, islanding.

\section{Introduction}

The first Electric Power Systems deployed were intended to meet local demands, from small plants and independently. Over the years this model has evolved. The growing need of energy has led to the construction of ever larger plants and an integrated system.

Special consumers need uninterrupted power supply and local power generation is the best option to ensure supply in case of grid failure. Others used local generation as a way to reduce energy consumption from the main network. In this way, the growing incentive to distributed generation (DG) has provoked a restoration of the world energy sector and consequent search or the development of increasingly efficient and reliable technologies.
With distributed generation in evidence, several studies have already been developed on the evaluation of already implemented systems, the development of optimization resources and the synchronization of the alternative source of local generation to the main electric grid.

This article deals with possible configurations of distributed generation system integrated in to a building and compares them to one another and to a system without local power generation, in order to counter their respective costs, financial returns, constraints and prerequisites. The use of data from an existing photovoltaic generation system allows the survey of the necessary conditions for the adaptation of the system for photovoltaic generation with battery bank, photovoltaicwind generation and photovoltaic-wind generation with battery bank, which together with the original configuration constitute the four hypotheses analyzed here.

\section{Distributed Generation}

Distributed generation isn't a new structure in world's power generation system. It emerged before transformers were perfected, when electrical energy distribution was made to consumers close to the generation.

\section{A. Definition}

Many are the definitions adopted for the Distributed Generation. In this article will be adopted as distribution generation the production of electricity in the place where it will be used (or nearly) in a decentralized way and independent of power, technology and source.

\section{B. Advantages and disadvantages of $D G$}

The installation of such a system involves the use of specific measurement, control and command equipment, 
in order to relate the operation of the generators to the control of loads for the best adaptation to the energy supply.

The expressive stimulus that has been observed in the last years to the distributed generation is justified by the several advantages that such system offers like the reduction in the cost of electricity supply due to the reduction in energy dependence from the main grid, especially a peak hours ${ }^{1}$, greater reliability of power supply, increasing availability of renewable energy sources that reduce the emission of pollutants into the environment and others.

Although the numerous advantages, due to the increase in the number of companies and entities involved, high cost of equipment used and others, DG also presents some disadvantages like the possible variation of the tariff due to the increase in the utilization rate of the system, the variation in the energy production of the system due to dependence of intermittent environmental conditions on some of the adopted sources, greater complexity in the planning and operation of electrical system, greater complexity in performing maintenance, in safety measures to be taken and in the coordination of the system and others disadvantages.

\section{Distributed generation today}

The interest in distributed generation has been renewed for the creation of a more sustainable electricity network, allowing the control of the peak times, the reduction of losses and environmental impacts and the increase of the insertion of renewable energy sources in the energy matrix. Its growth has increased considerably in Brazil and the world. The basic premise for the deployment of these networks is the automation of their entire distribution structure to the consumer, a scenario opposite that of the traditional system.

In developing countries, the use of distributed renewable energy is mainly used as a tool to expand access to energy (particularly in rural areas); in developed countries, is the answer to the demand for selfsufficiency and a desire for reliable and quality electricity by consumers connected to the grid [5].

Although the decrease of approximately $22.6 \%$ compared to 2015 , in 2016 a total global investment of US\$ 241.6 billion was made in renewable and fuel sources. This investment resulted in a $161 \mathrm{GW}$ increase in global renewable energy capacity.

The top five countries in terms of capacity or generation for bio-power, geothermal, hydropower, solar PV and wind power until the end of 2016 involved countries located in the European and Asian continents, as Germany, China, Russia, Spain, Japan, Italy and some countries of America, like USA and Brazil.

1 The period composed of 3 consecutive daily hours defined by the distributor. In this period the concessionaires practice higher tariffs.
In Brazil, by the end of October 2014, it heard the registration was of 1000 consumers, presenting an increase of 731 connections in the following two months. According to ANEEL, among the new installations, 96.8\% use solar PV power totaling more than $13 \mathrm{MW}$ in installed capacity.

\section{The operation of the island system}

In order to ensure the good performance of the local generation system without affecting the operation of the primary network, some minimum requirements for control, protection, installation and location must be defined by the energy concessionaires and/or regulator organ. An example of these conditions is that, if there is a lack of utility supply in a network that contains distributed generators, they must be automatically disconnected at a predetermined time by the local utility, returning only after power is restored. This isolation process is known as islanding.

There are cases where the islanding of the system is done intentionally, as in cases of scheduled maintenance as will be proposed in this article or for isolation of the system at times when it's able to supply the demand itself. There still cases in which the islanding of the system is done intentionally, as in cases of scheduled maintenance or, as will be proposed in this work, to isolate the system at times when it's able to supply the demand itself.

In situations of islanding of systems that contain sources that depend on intermittent resources (solar and wind, for example), it's indispensable to use energy storage devices that can meet demand during periods of zero or insufficient generation. In two of the four arrangements of distributed generation systems studied in this article there is the proposal of adding storage elements that allow reallocating part of the local generation in a certain period of the day.

\section{Basic system detailing}

For the development of this study, some of the characteristics and measurements carried out at the Centro de Pesquisa em Energia Inteligente (CPEI) located at Campus II of Centro Federal de Educação Tecnológica de Minas Gerais (CEFET-MG) were adopted by basis. The building was built by the CEMIG concessionaire in partnership with CEFET-MG and hosts research un the area of Bioclimatic Architecture, Electrical Engineering and Mechanical Engineering, with a focus on interdisciplinarity and better energy utilization. The whole project was designed to build a building capable of making the most of passive energy with natural lighting and ventilation and to reduce the use of active energies such as artificial lighting and air conditioning. There is also the use of water heating through solar panels and a generation system with photovoltaic panels interconnected to the network, among other. 


\section{A. Demand curve}

To obtain the demand curve of the building, a survey was made of the main loads of the building and their respective nominal power values. The power of devices like fridge and water drinker, which have intermittent operation, was defined by the average power, based on data collected in previous measurements that allowed to determine how many times and how long each appliance remained connected.

In order to estimate the total daily demand, loads were separated between those that remain in constant operation (such as water drinker, fridge and some computers) and those depending on the time of the day (such as building lighting) or the number of people in the building (like other computers, fans and others). Loads of sporadic use were disregarded in this survey.

At the end of the survey, the curve present in Fig. 1 was obtained, showing that the power demanded by the building exceeds $3.5 \mathrm{~kW}$ and has a minimum near 500 W. This curve corresponds to the demand from the months of March to December. That's why in January we have the holiday period, so in this the demand was considered null. In February, as there are fewer people on campus, only $50 \%$ of demand this month will be considered for calculation purposes. It was noted that peak demand coincides with the period when there are supposedly more people in the building.

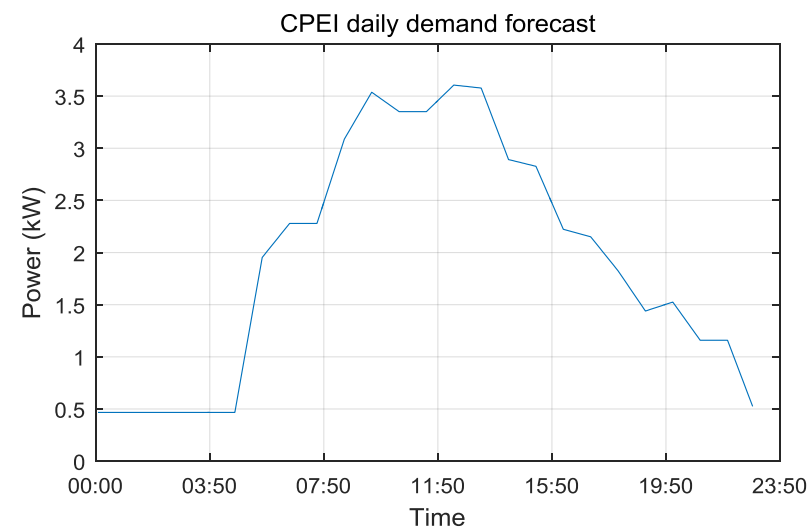

Fig. 1. CPEI daily demand curve forecast. Prepared by the author.

Based on estimated demand curve and using the photovoltaic generation data of the existing system in the CPEI building, three other configurations are proposed. In cases where there is the addition of battery banks, these are sized in order to supply at least the demand of the building during rush hour.

\section{B. Solar System PV}

The building in question already has a local photovoltaic generator able to produced almost 3.86 MWh a year. In Fig. 2 and Fig. 3 the average daily power curves of the generator can be observed in two months of the year, together with the respective expected demand curves and the deficit, which will be supplied by the connection of the system to the main grid. The selected months represent those in which there was be highest and lowest peal power generated.

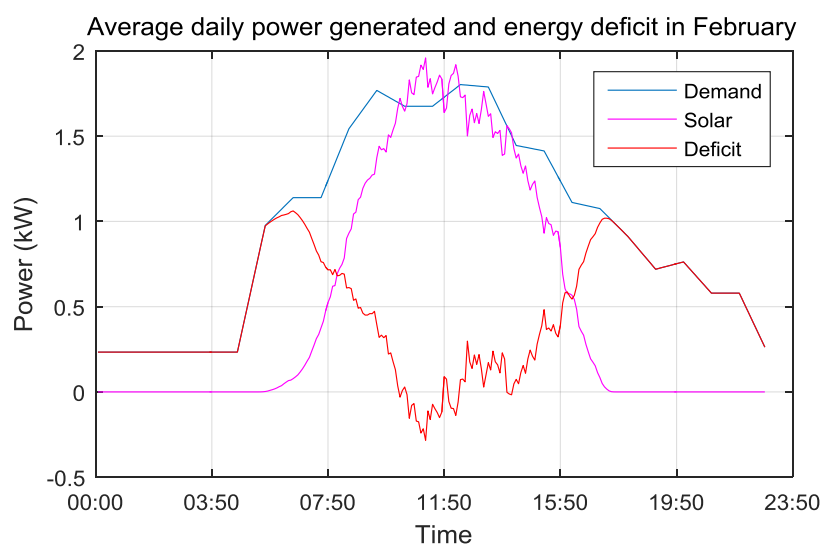

Fig. 2. Average daily power of the generator, building demand and resulting deficit in February.

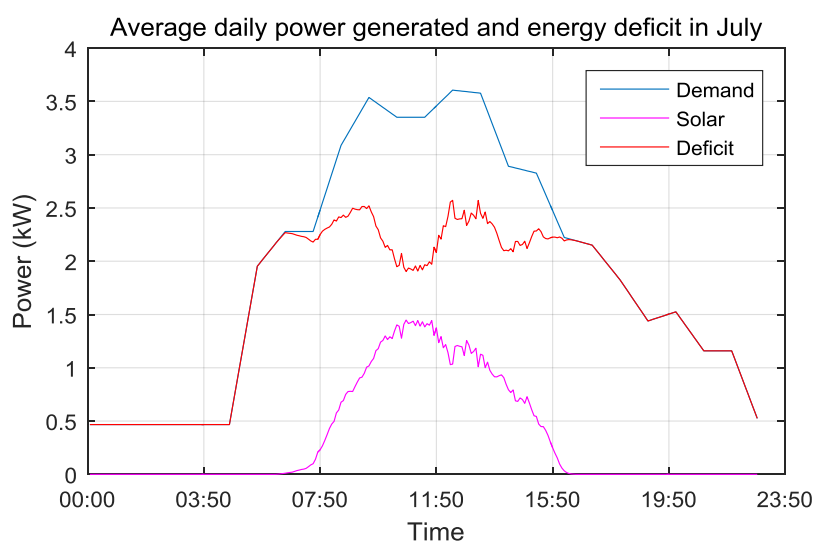

Fig. 3. Average daily power of the generator, building demand and resulting deficit in July.

The graphs show the strong relationship between the seasons of the year and the generation levels of the PV system, with the month of February being the one with the highest generation levels and July the lowest, corresponding respectively to summer and winter (in the southern hemisphere). This is because it's a system closely related to the level of incident solar radiation, which varies during the year.

\section{PV solar system with batteries}

Considering that the energy generated only with PV system concentrates in part of the day, because it depends directly on an intermittent source, it's interesting that the energy generated is distributed more well in order to attend the others schedules, especially those which the concessionaire's tariffs are higher, and the local generation is smaller or nil. Such regulation can be done through the use of energy storage, such as a battery bank.

In this article the battery bank design is based on the case where it should store more amount of energy for peak hours (corresponding to the period between 5 and $8 \mathrm{pm}$ according to the local concessionaire). Analyzing the collected data, the month of May registered the highest energy deficit $(5957 \mathrm{kWh})$. A battery bank of the type $\mathrm{OPzS}$ was selected, the dimensioning of which is detailed below in equations (1) and (2). 


$$
\begin{gathered}
\mathrm{I}=5957 / 24=248.21 \mathrm{~A} \\
3 \mathrm{~h} \rightarrow 3 * 248.21=744.63 \mathrm{Ah}
\end{gathered}
$$

Considering a discharge above $80 \%$ as deep, the minimum capacity of the battery should be $930 \mathrm{kAh}$. From the manufacturer's catalog selected two types of batteries were chosen: 1065 Ah e 1278 Ah. The return on investment for both batteries will be evaluated later.

\section{Hybrid system}

In addition to the fact that the photovoltaic system presents restricted hours of energy production, it was observed that the generation is rarely sufficient to supply the expected demand and, when it is, it's for a short time. Was observed in the monthly balance between generation and deficit for the system only with solar photovoltaic generation (with and without battery bank) that it isn't sufficient for supply the demand, proving the need for an auxiliary generation source to reduce such deficit. Under normal circumstances, such a complementary role is developed by the concessionaire. Wind energy is one of the most applied energy sources as a complement to solar energy.

According to the wind turbine manufacturers consulted, Tab. I shows a comparison between the three most efficient compact models. Small turbines were selected, due to the available area for installation, and vertical axis, as they didn't depend on the wind direction variation.

Tab. I - Comparison between WS-0.15B, Falcon $600 \mathrm{~W}$ and CXF300-I turbines. (Source: Windside; WePower; Typmar)

\begin{tabular}{|l|c|c|c|c|}
\hline $\begin{array}{l}\text { MANUFACTURER/ } \\
\text { MODEL }\end{array}$ & TYPE & $\begin{array}{c}\mathrm{V}_{\text {starter }} \\
(\mathrm{m} / \mathrm{s})\end{array}$ & $\begin{array}{c}\mathrm{V}_{\text {nom }} \\
(\mathrm{m} / \mathrm{s})\end{array}$ & $\begin{array}{c}\mathrm{P}_{\text {nom }} \\
(\mathrm{W})\end{array}$ \\
\hline Windside/ WS-0.15B & Savonius & 1.5 & 20 & 120 \\
\hline WePower/ Falcon 600W & Darrieus & 2.7 & 13 & 600 \\
\hline Typmar/ CXF3000-I & Hybrid & 2 & 13 & 3000 \\
\hline
\end{tabular}

It's observed that the Savonius-Darrieus model is the most efficient among the presented models and also the only one able to generate the necessary power to supply the remaining demand of the building.

Data from the wind speed from CPEI's meteorological station in the building for the same year in which solar generation data were collected were analyzed. The wind speed curves for the months with the lowest and highest recorded peak velocity are shown in Fig. 4 and Fig. 5, respectively. The months of January and February were the ones that presented lower wind speed during the day. However, these are the months of higher PV generation and the speeds recorded in the months of lower solar generation are sufficient to star the wind system, so that one source has its peak in the period of less generation of the other.

The CXF3000-I hybrid turbine and data provided by its manufacturer [6], cited in Tab. I, will be adopted in this paper. From the power curve provided by the manufacturer, the mean power curves generated by the wind turbine are obtained. A reduce of $21 \%$ was observed in the energy deficit for the total of the year, in relation to the one observed in the solar system, with an add of almost $2.87 \mathrm{MWh}$ in the yearly generation come from the turbines.

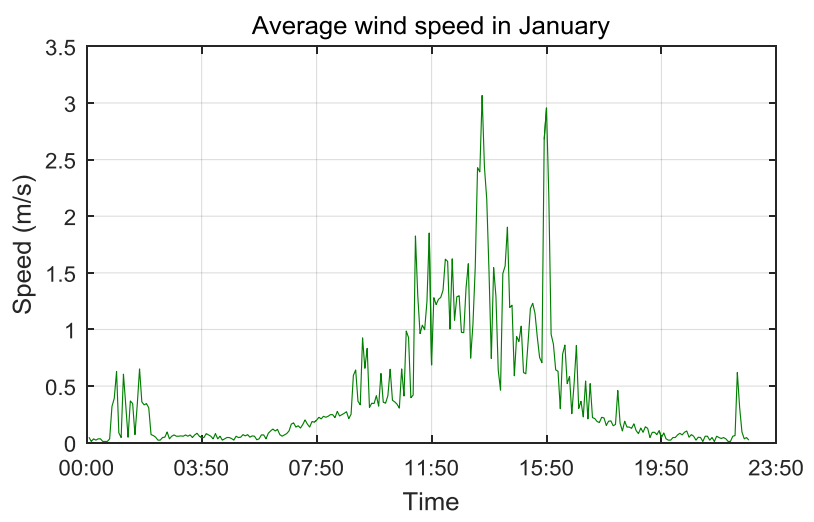

Fig. 4. Average wind speed in January.

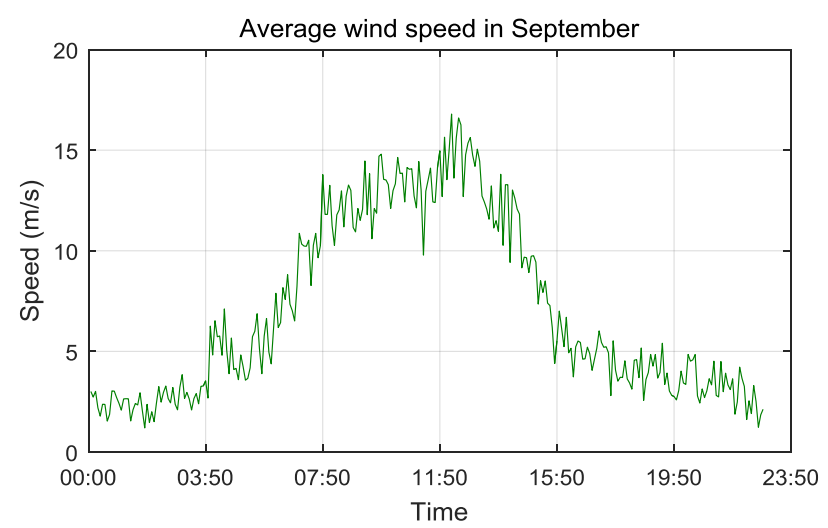

Fig. 5. Average wind speed in September.

\section{E. Hybrid system with batteries}

It can be observed in the graphs of Fig. 4 and Fig. 5 that wind generation has a similar behavior to photovoltaic generation when comparing generation period. However, in wind generation there is power generation for more hours of the day. Once again, in order to better distribute local generated energy, it's intended to add a bank of batteries to meet the demand in the schedule of higher energy tariffs.

Again, the case in which more energy will be stored is analyzed. In this case, the month of June is the one with the highest energy deficit, with a difference of only $3 \mathrm{Wh}$ for the case of the PV generation $(5.955 \mathrm{kWh})$. With values so close, the same battery bank sized for the PV solar system is suitable for the hybrid system.

\section{Comparative analysis of the arrangements}

The curves of Fig. 6 and Fig. 7 present the energy deficit, for the months of April and October, for each kind of arrangement of the generation system. This deficit is the result of the difference between the curves of CPEI demand and total generation and must be supplied by the connecting the building system to the local energy concessionary. 


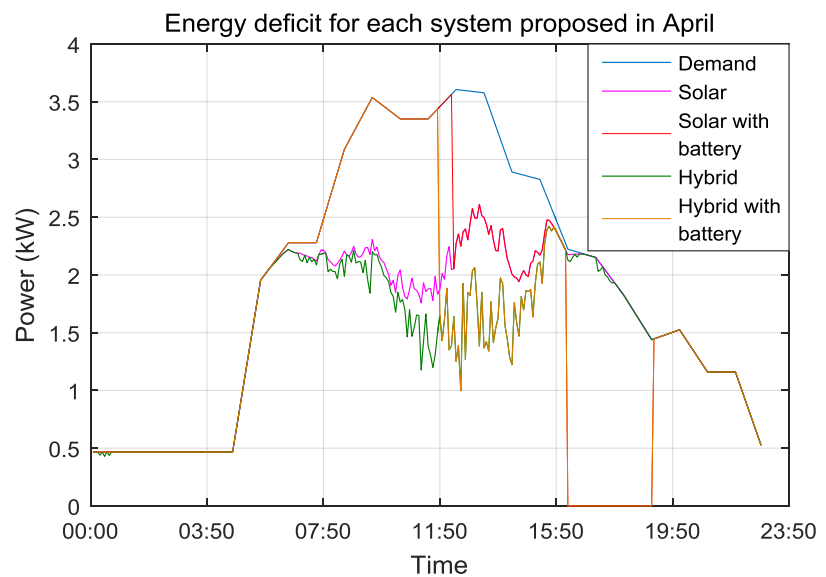

Fig. 6. Energy deficit curves for each type of generation system arrangement in April.

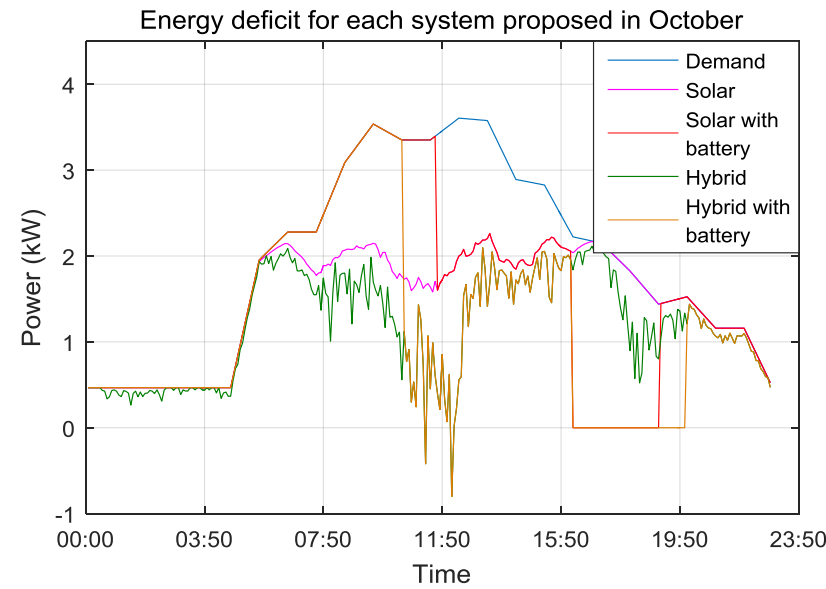

Fig. 7. Energy deficit curves for each type of generation system arrangement in October.

In all months of the year, it was observed that the hybrid system present lower deficits, reducing the concessionary energy consumption, except for the months of January and February, where the registered wind speed was extremely low, making the total generation of the hybrid system practically equal to that of the system photovoltaic system.

In the system curves using batteries, the deficit curve is equal to the demand curve shown in Fig. 6 and Fig. 7 to some extent. This is because, since the beginning of the day, the local generated energy is directed to the charging of the battery bank, so, in this period the building load is totally suppressed by the energy concessionary.

At the end of charging the batteries the energy generated by the arrangement is used to reduce the mains power consumption or take it to zero. The end of the charging of the battery bank can be observed in the figures when there is a first sharp fall in the curves of the system with battery bank. In the hybrid system with batteries, these usually load in less time, especially in the months of greater wind generation. The second drop, which takes both system curves with batteries to zero, happens at 5 pm every month and presents the moment when the battery bank is activated to fully meet the demand of the building in the peak hours of the concessionaire's tariffs.
When comparing the April and October curves for the battery systems, it's observed that in October the bank autonomy time exceeds the minimum time of 3 hours in the hybrid system. The same happens in the months of September, November and December. In these months in the night, when PV solar generation is zero, there is still expressive wind generation (possible considering the multiplicative factor under the measured speed), which causes the energy deficit to be lower in this arrangement and the battery bank discharge more slowly.

The addition of the wind generator also allowed several hours of system autonomy to be recorded in some months, such as August and September, in addition to the months of June, October, November and December, which recorded small periods of self-sufficiency. These periods can be seen in the curves presented when the deficit curves becomes negative.

Tab. II shows the energy forecast to be acquired from the concessionaire in order to complement each of the arrangements studied in comparison to the system without the use of alternative sources of local generation. It can be observed that the photovoltaic generation system is able to produce approximately $3.48 \mathrm{MWh} /$ year, while the hybrid system, assuming the wind speed adopted, could generate almost 5.92 MWh/year.

Tab. II - Forecast of the energy ( $\mathrm{kWh})$ to be purchased from the concessionaire for each arrangement.

\begin{tabular}{|c|c|c|c|c|}
\hline \multicolumn{6}{|c|}{ ENERGY (kWH) TO BE PURCHASE FROM THE CONCESSIONAIRE } \\
\hline $\begin{array}{c}\text { Without } \\
\text { local source }\end{array}$ & $\begin{array}{c}\text { Solar } \\
\text { PV }\end{array}$ & Hybrid & $\begin{array}{c}\text { Solar PV } \\
\text { with battery }\end{array}$ & $\begin{array}{c}\text { Hybrid with } \\
\text { battery }\end{array}$ \\
\hline 15048.7 & 11571.2 & 9128.4 & 11594.3 & 9128.2 \\
\hline
\end{tabular}

The difference observed between the values of energy purchased for the systems with and without batteries due to the treatment of the data collected. Theoretically the amount of energy acquired in the configurations with and without storage elements differs only by the reallocation of part of the local generation at another time of the day.

By analyzing the local concessionaire ${ }^{2}$ energy tariffs during the period in which this study was carried out, the cost of energy at rush hour is almost five times higher. This difference is due to the large variation in the tariff of use of the distribution system (TUSD). Out of peak hours TUSD reduces to $4 \%$ of the amount charged during the tip. In the survey carried out, it isn't considered the cost of availability charge by the concessionaire for the months in which the demand of the building is null, since, the CPEI is included in a larger system, so that there's always a minimum consumption different from zero in the installation total. They are also considered constant rates throughout the year.

Based on the considered tariffs, it was observed that, although systems with and without battery have approximately the same amount of energy to be purchased, there is a significant gain in reallocating local 
power generation to supply the system during peak hours. The use of storage elements made it possible to reduce costs by $36.66 \%$ in the purchase of energy for the solar system and $42.18 \%$ for the hybrid system.

Clearly, the local generation sources and storage systems are added, less energy is purchased and less costly. For the solar system, even without the use of batteries, $17.66 \%$ of the value spent on the system without alternative sources can be saved annually, since in this arrangement the energy to be purchased from the concessionaire is equivalent to approximately $76.86 \%$ of the total demand forecast for the CPEI. For the hybrid system, there is the annual saving of $30.08 \%$ of the cost of the system without local generation, with a total demanded energy $39.34 \%$ lower than the expected demand.

\section{Conclusions}

Among the configurations proposed for the local CPEI generation system, several factors must be analyzed before choosing the most suitable model. With respect to the physical limitations there's the wind generation system that required a minimum speed to function properly and solar generation in which the location of the photovoltaic plates and their positioning directly interfere with the generation. Often the project is limited by the size of the equipment, as the wind system where lack of space prevents the installation of more turbines or the choice of a large one, capable of generating more energy.

The equipment used in the study for cost forecasting isn't even produced in Brazil. The selected wind turbine, for example, is produced by Typmar, a Chinese company, and costs US\$ 7500.00. The manufacturer of the selected battery bank has resellers on all continents and the battery banks considered have a suggest cost of $€ 695$ (1065 Ah) and €803 (1278 Ah), which may vary according to the dealer.

The analysis carried out, after conversion to local currency (real), take into account that the cost of the equipment could double with the costs of import and installation. The battery bank has a limited life expectancy according to the number of charge/discharge cycles performed, requiring regular replacement and maintenance. If the selected bank is $1065 \mathrm{Ah}$, it has a useful life of approximately 5 years and 3 months. For the bank of $1278 \mathrm{Ah}$, the useful life would be 6 years and 9 months, therefore, 1 year and a half longer than the first bank.

At first, the model adopted for the hybrid system with the use of the battery bank as storage element was the most attractive because it presented the lowest cost in the purchase of complementary energy in the local concessionaire. However, it is also the one that requires more investment. Although the CPEI already has a photovoltaic generation system, for its adaptation to the hybrid system it would be necessary to acquire the wind generator and the batteries. Considering that the tariffs charged by the local concessionaire are kept constant over the years, it would take approximately 16 years for the investment to be paid only with the economy of the hybrid system with batteries compared to the system without alternative sources, with a difference of 2 months according to the bank of batteries selected.

For the photovoltaic system with batteries, the investment would be paid for the economy of the system after a period of 1 year and 9 months, for the bank of $1065 \mathrm{Ah}$, or 2 years, for the bank of $1278 \mathrm{Ah}$. Since the choice of the bank of 1278 Ah adds only 3 months to the return on investment and increases the battery bank change time by 1.5 years, this is a better option.

In order to evaluate the economic profit of the main proposed configurations, it is considered an opportunity cost. This refers to the profit obtained on a second investment option. In this paper, the opportunity cost considered is the monthly income that would be obtained by applying the value of the savings investment. Despite the operating profit (economy of the photovoltaic system in relation to the system without alternative source) observed, the economic profit (difference between the operating profit and the opportunity cost) is negative, indicating that the investment of the amount necessary to adapt the savings system is more advantageous.

Therefore, the photovoltaic system with batteries is the most advantageous arrangement among the four proposed models. However, with the assumptions considered, it's still an expensive system to implement when considering the use of the selected battery bank.

For a more realistic analysis, the installation labor costs should be accounted for and the necessary ancillary equipment, such as the charge controller for the batteries and protective devices, should be analyzed.

\section{References}

[1] DIAS, M. V. X.; Geração Distribuída no Brasil: Oportunidades e Barreiras. 2005. 143 f. Dissertação (Postgraduate in Energy Engineering). Universidade Federal de Itajubá, Itajubá. 2005.

[2] PÁDUA, M. S.. Técnicas digitais para sincronização com a rede elétrica, com aplicação em geração distribuída. 2006. 165 f. Thesis (Masters in Electrical Engineering). Universidade Estadual de Campinas, Campinas. 2006.

[3] MALFA, E.; ABB on Sustainable Energy Markets, Università di Brescia, 2002.

[4] FILHO, W. P. B.; AZEVEDO, A. C. S.. Geração Distribuída: Vantagens e Desvantagens. In: Simpósio de Estudos e Pesquisas em Ciências Ambientais na Amazônia, 2, 2013. Belém, Pará. Anais... Belém, 2013.

[5] RENEWABLE ENERGY POLICY NETWORK FOR THE 21ST CENTURY (REN21). Renewables 2017: Global Status Report. Available in: http://www.ren21.net/wpcontent/uploads/2017/06/GSR2017_Full-Report.pdf. Access in: 25 de ago. 2017.

[6] TYPMAR. CXF3000 W Turbine. Available in: http://www.typmar.com/case-item-301.html. Access in: 14 de maio de 2017. 